\title{
Practicing Management Information System in Bangladesh
}

\author{
Md. Saiful Bari \& K.M. Nafiul Haque \\ Department of Brac Business School. Brac University, Bangladesh \\ Email: saifulbari4000@gmail.com
}

\begin{abstract}
Management Information Systems is an essential factor in the existing world. The goals of the study to create eagerness for the usage of MIS in every sector in all activities for the betterment of condition. In this paper, we have tried to existing fundamental associated subjects of MIS (that ability literature assessment and it consists of about MIS, Computer software, DBMS, telecommunication and networking), objectives, beneficiary persons, way of finding information, corporation assessment (it consists of historical background, company overview, practices of MIS in this organization), MIS practices and challenges in Bangladesh and ultimately providing likely recommendation.
\end{abstract}

Keywords: Information and verbal exchange technologies, records systems research literature, developing countries benefits of MIS, MIS model

\section{Introduction}

In order to reply the research, question a literature study, semi structured interviews and a survey have been conducted. During the late 90's, Bangladesh has considered a growing increase of the ICT industry. Initially, the favorable tax coverage of the government of Bangladesh in 1998 accompanied by way of the world affordability of personal computer systems have had excellent have an effect on the utilization of computer. The favorable import tax policy on computer systems and pc add-ons for the duration of that time was once one of the timely steps taken through the government of Bangladesh. From then on, in accordance with the world trends, both personal and public sectors in Bangladesh caught up with superb utilization of records technology. The formation of a considerable number of software program development companies is a properly indication of this development. Recently, wide spread telecommunication outreach all over the U. S. has given the ICT industry in the United States an introduced impetus to go forward. According to industry specialists (BASIS leaders), the latest development in joint ventures and business collaborations among Danish agencies and Bangladeshi software program businesses would help significantly in sustaining

the enviable boom in the export earnings? Some of these projects are already in vicinity and many others are either in the pipeline or perceived to be coming in the near future. Another factor that has contributed to the current excessive export increase is the effect of the multinational telecom companies. These companies while operating in Bangladesh utilized the neighborhood IT region for many of their worldwide initiatives giving a good software program export chance for Bangladesh. Information is a set of categorized and interpreted data used in decision making and it has also been defined as "some tangible or Considering the definition for MIS, one of the 
popular definition describes management data machine (MIS) as "an organizational technique of presenting past, present and projected information related to inside operations and exterior intelligence. It helps the planning, control and operation functions of a company through furnishing uniform facts in the applicable time frame to aid the choice makers". The facts in MIS describes the firm or one of its primary structures in terms of what has befell in the past, what is occurring now and what is possibly to happen in the future. The facts are furnished in the shape of reports and outputs of mathematical simulations. There are two types of reviews namely, periodic and exclusive report. All managers use the statistics output as they make decisions to remedy the firm's problems. A management statistics system has additionally been defined as "an integrated consumer computing device system for providing statistics to help operations, administration and selection making functions in an organization. The gadget utilizes computers, guide procedures, models for analysis, planning, manage and choice making, and a database". All these definitions give a concise perception of MIS as a total intangible entity which serves to decrease uncertainty about future state or events". There are distinct levels of decision making, for which records can be described as:

1) Source

2) Data

3) Inferences and predictions drawn from information

4) Value and options

5) Action which involves route of action.

Management facts gadget has a motive to meet the regularly occurring statistics desires of all the managers in a company or in some subunits of the organization. A subunit can be based on useful areas or can be considered at administration levels.

\section{Literature Review}

MIS refers extensively to a computer-based device that gives managers with the equipment for organizing, evaluating and effectively running their departments. In order to grant past, existing and prediction information, an MIS can encompass software that helps in decision making, records resources such as databases the hardware sources of a system, choice assist systems, people management and challenge administration applications, and any computerized methods that enable the branch to run efficient. Business manner has been made easier to execute with the aid of developing some corporation-based Software or structured software program such as TPS, MIS, DSS are those who serve management tiers by offering facts and records from internal and external sources. As their non-flexibility in operation and overall performance and non-response to the concurrent change, the enterprise wide software such as ERP, SCM, and CRM has been developed. ERP integrates all the information from branch and centralizes them. SCM and CPM are serving to make environment friendly furnish and purchase, finding potential consumer at minimum fee and serving them best. All these factors help to make enterprise technique more efficient.

A Database Management System (DBMS) is a set of applications that controls the creation, maintenance, and the use of database allows groups to vicinity manipulate of database improvement in the arms of database directors (DBAs) and different specialists. 
A DBMS is a gadget software bundle that helps the use of integrated series of facts information and documents known as databases. It lets in unique person utility packages to effortlessly access the same database. DBMSs can also use any of a variety of models, such as the networker model. In massive systems, a DBMS lets in users and different software program to shop and retrieve records in structured. Instead of having to write laptop programs to extract information, user can ask simple questions in a question language.

Hardware refers to the physical parts of a computer and related devices. Computer hardware is formed by using various peripherals those are related with every other. Hardware is a comprehensive time period for all of the bodily parts of a computer, as extraordinary from the data it consists of or operates on, and the software that presents guidelines for the hardware to accomplish tasks.

Telecommunication is the exchange of records over considerable distances through electronic means. A complete, single telecommunications circuit consists of two stations, every geared up with a transmitter and a receiver. Networking is the practice of making contact and changing information with other people, agencies or institutions. Usually, networking happens with other humans who have pastimes in comparable areas. The goal of the networking relationship might also be to similarly your non-public employment opportunities or to cultivate new customers or the growth of business relationships. Networking is also a time period of art used in the computer industry. Different wireless gadgets such as Bluetooth, Wi-Fi, we max , 3G has made instantaneous internet access, enabling chatting, sending electronic mail messaging that have confirmed new sphere in the field of e-business.

Objectives: (1) MIS help decision makers, with the aid of imparting the required information at a range of degrees of decision making and consequently greatly assist the business enterprise to obtain its dreams and objectives; (2) Make up to date for going through a number essential situation; (3) Know about the perception of MIS as an area of find out about and as an area of business; (4) Know about the situation of MIS practices in the world as properly as in Bangladesh; (5) Know the things to do of MIS of an enterprise; (6) Know about the MIS practices from global perspective; (7) Identify the issues of practices of MIS in Bangladesh; (8) Provide tips to remedy the problems for excellence overall performance in MIS.

\section{Research Method}

The Primary Data was gathered from Head IT Infrastructure Managers in the Information System department of Humac Lab by way of taking bodily interview and accumulating documentation which gave an insight into the methods being followed with regards to the functioning of MIS. An interesting methodological discovering from the surveyed literature is that there is considerable focus of the need to look at the interconnection of tiers of analysis. In a survey article written about 10 years ago, which gives a fascinating comparative groundwork for our survey of current work, Sahay and Walsham (1995) argued the want for multi-level analysis, "The process of IT use in growing nations is a complicated phenomenon and it commonly entails actors at a range of levels. It is vital to study the interplay of these extraordinary actors on the procedure of IT implementation and use" (p. 118). Few papers were doing that 10 years ago, however now they are pretty common, and frequently with more state-of-the-art views of what constitutes an "actor" 
than in the quote above. For example, Sayed and Westrup's (2003) article on ERP systems in Egypt, discussed earlier, appeared at actor-networks involving world organizations, local companies, governments and resource organizations. With admire to labeling their methodological approach, the majority of the studies, if they tackle this explicitly, declare to be interpretive. Very few researches in our survey adopted a positivist strategy with mentioned hypotheses, units for records collection, statistical inference etc. It is past the scope of this paper to analyze the precise motives for this; however, it is truly true that many of the research questions and challenges tackled through IS researchers in our survey would now not have lent themselves naturally to a positivist methodology. Many of the studies come throughout as pretty stable in methodological terms, with in-depth case studies being common, for example, the two-research described in Walsham (2002). This contrasts strongly with the typically "thinner" research mentioned in Sahay and Walsham (1995) a decade earlier. Perhaps surprisingly, bearing in mind the importance of action in addressing issues of development, motion lookup studies are truly rare, though the over 10-year research program in South Africa and some other place summarized by means of Braa and Hedberg (2002) is an outstanding exception. Overall, reading the survey paper of Sahay and Walsham (1995), and comparing it to our in-depth analysis of materials from 2000 onward, suggests to us that growth has been completed over the ultimate decade in research on IS in growing countries. However, we now flip to an ahead look to attempt to see where and how lookup could be advanced further.

\section{Findings and Discussions}

Interview:

MD. MUBIR M. CHOWDHURY

\section{CO- FOUNDER \& CEO Humac lab}

According to MD. MUBIR M. CHOWDHURY CO- FOUNDER \& CEO of Humac lab, IT suggests Information Technology. It is a big platformer and greater or less each people use statistics technology. It is in office, industry, home. IT assist to human beings join every other. In case of individual, official, professional, personal, globally in the entire world. IT enterprise is the part of ICT. IT industry assist to work fast, shop time, extra efficacy in the work, maintain the work accuracy and much less manpower. Frist of all, work quicker earlier than the IT the enterprise desires more work for instance one hundred worker but now they want 20 workers is properly for this work. The work efficiency is growing due to the fact of the management facts system. Today, the top-class office is connected to the low or middle-class officer or worker. People can easily find information about corporation product and service. Because of administration statistics device all facts are nicely organize so that corporation can locate their hassle easily and resolve as quickly as possible. Business to Business (B2B) type company need a lot of information about the agency work, company existing work, agency product value, agency product price, organization future targets, organization previous business reports, business enterprise ability or capital, organization funding power, enterprise culture, employer effectivity and so on. This is a large measurement of records is making efficiently solely through administration information device that cause most of the huge employer have their administration data system.

Problems to enforce MIS systems In Bangladeshi companies: (1) Poor or insufficient 
infrastructural facilities; (2) Unwillingness to make investments cash in this sector; (3) Less net speeds; (4) Lack of awareness; (5) Poor knowledge about practices or importance of MIS; (6) Lack of expert technique human resources; (7) Rearing ordinary system; (8) Lack of eagerness to acquire new things.

Recommendations for fixing the problems to enforce the MIS structures to attain operational excellence in Bangladeshi enterprises: $\neg$ Making excellent infrastructural facility to undertake changing situation. $\neg$ Making fund to introduce or run MIS structures in organization. $\neg$ Taking a number of attention things to do to understand the essence of MIS structures in this era. $\neg$ Trying to be self-dependent on technological sector. $\neg$ Providing coaching or workshop for making ability human resources. $\neg$ At last, authorities guide is too crucial to put into effect the MIS systems in Bangladesh.

Management Information System Practices in Bangladesh: The current scenario of MIS practices in Bangladesh is improving day by way of day. Every branch no longer solely private but additionally govt. companies are attempting to exercise MIS gadget in their activities. Some of the agencies have superior too far. These consist of Bank, Telephone operator, University, Organization, Hospital etc. Some MIS practices in Bangladesh are highlighted below: Banking systems are now absolutely altering due to internet. All the transactions can be possible through electronic means. Account holder can withdraw or credit score cash to ATM sales space barring going to bank. Now items and services are bought over the internet. Example of e-commerce related web sites www.chokra.com Many departments of Bangladesh govt. have already brought MIS structures of their activities .Electricity bill can be supplied thru mobile cellphone .Mobile phone is used to purchase increase instruct ticket .Varsity admission shape and admission result can be known by means of cellular telecommunication service . Now hospitals receptionist can furnish all the statistics about affected person within a minute due to keeping database gadget . All the leading groups are used net based gadget to recruit their employees . There is a lof of lookup on the approaches, methods and applied sciences for the format and improvement of MIS. However, there are a few articles that cowl the effect of Management Information Systems on planning and decision making. While there are no universally popular definitions of MIS and those that exist in literatures are simply prejudices of the researchers (Adeoti-Adek eye, 1997). Lee, (2001) defined MIS as "a gadget or system that offers statistics needed to manage organizations effectively". Additionally, Baskerville and Myers (2002) generally define MIS as "the development, use and software of records systems by using individuals, companies and society". In his study, Becta (2005) describes a data machine as "a device consisting of the community of all conversation channels used inside an organization". In their study, Laudon and Laudon (2003) have described MIS as "the learn about of records structures focusing on their use in commercial enterprise and management". The abovementioned definitions showed that MIS has underlined the development, software and validation of relevant theories and models in tries to encourage fine work in the area. Referring to the literatures, the area of Management Information Systems (MIS) has had a variegated development in its fairly short existence span. MIS has developed its very own theme of research and research 
(Baskerville and Myers, 2002). Tracing previous literatures, we can document that all through its first few decades, MIS targeted on the facts in the context of: - Electronic records processing which contains out transaction processing functions and archives particular factual data. - Management reporting systems which scrutinize the operational things to do of an organization, imparting summaries, data and remarks to management. Only all through the ultimate two decades, the MIS area has shifted to the primary, regarded the $2 \mathrm{~d}$ kind of communication, namely, instruction-based. This has grown to be recognized as the domain of expert structures (Sasan Rahmatian, 1999). In attempts to assessment posted studies on MIS and articles, Alavi and Carlson (1992) have identified famous lookup topics, the dominant research perspective, and the relationship between MIS research and practice. In contrast, Baskerville and Myers (2002) have examined the MIS discipline and discovered a consistent shift of MIS research from a technical focus to a technologyorganizational and management-social focus. Skyrius (2001) underlines the choice maker's attitudes in the direction of specific factors influencing the fine of business decisions; these elements include information sources, analytical tools, and the function of facts technologies. Handzic (2001) also will pay attention to the have an effect on of information availability on people's ability to system and use records in quick and lengthy time period planning and in selection making tasks. He revealed that the higher the avail capability of information, the higher the impact on both effectivity and accuracy of commercial enterprise decisions. Liu and Young (2007) speak about key information models and their relationships in commercial enterprise decision aid in three specific scenarios. The authors proved that world groups are in increase due to the Enterprise Applications System supplied through contemporary IT tools such as Enterprise Resource Planning (ERP), Knowledge Management Systems (KMS) and Customer Relations Management (CRM) to decorate the effectivity and effectiveness of the Decision-Making process.

In order to enhance the financial organizational functionality and beautify its stage of opposition in the market, monetary organizations must understand the dimensions of the Information Management, and really outline and strengthen the assets in case of human, technological, and inner operations, amongst others, and control them nicely across the organizational

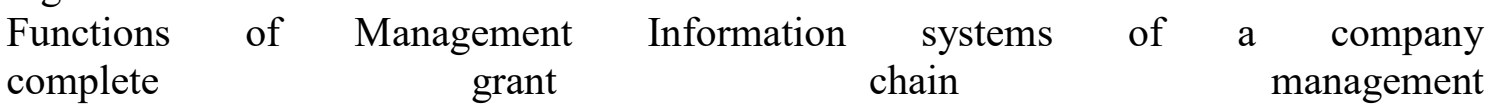
they have built unique \& sturdy sourcing and furnish management methods that supply fine services to their business partners. They are properly recognized for their information and professionalism in dealing with the whole technique from thought to fulfillment. Fashion Design:

They complement their client's sketch department. They create styling according to client's specs on fabrics, clothes and accessories. They research on patron needs and future trends. Using brand new technology, they hold abreast of the developments in the fashion industry and provoke brand new products. Raw cloth sourcing:

Their robust group of researchers will supply and evaluate the mills and accessories manufacturers of the yield. With their strong global network, they only seek yarn, material and add-ons at the great best and aggressive rate for their clients. 
Sample Development:

With their well-established relationships with factories together with some their very own factories, they are capable to get samples at the proper quantity, at the proper time. They ensure that samples are made in accordance to the client's specifications, they also recreate and regulate famous styling to suit client's demand. Order Negotiation:

They safeguard client's hobby at all times. They always offer a very aggressive fee with quality. They filter the factories cautiously and make certain them client's expectations are met accordingly.

Work in growth supervision:

They accept as true with that the solely way to ensure exceptional and well timed transport is to screen an order from cloth production and dyeing to delivery to the production line.

Yarn, Fabric \& Accessories Research:

They are in the technique of setting up a one of a kind "Yarn Fabric Library" which will be their client's elite lookup center. The library will preserve their customers updated of the cutting-edge trend and advocate them of the USA of production which will permit them to revel in preferential tariffs and duties.

Production planning \& manufacturing control:

Together with their skilled staff, they layout and prepare the complete production system systematically. Every steps of the technique are cautiously planned and recorded. They monitor each day and weekly output assuring delivery closing dates are met.

Factory strength:

They have a community of more than 300 factories in over 20 nations in a range of continents. The factories specialize in all types of apparels. Their contrast crew and pleasant controllers always make sure that all the factories are nicely outfitted and qualified.

Quality assurance:

They ensure that factories produce in accordance to their client's necessities and specifications. Their group of nice controllers will conduct regular tests to assure great is maintained at all times. Their QCs specialize in uncooked substances to completed goods inspection. They are also equipped with knowledge to give technical help to manufactures and high-end equipment to habits precise checks.

Logistic coordination \& export documentation:

They take care of all fundamental shipping preparations and ensure all documentary processes are made for that reason so that all shipments reach their customers promptly. 


\section{Conclusion}

An administration records device (MIS) is a system that provides statistics wanted to manipulate organizations effectively. Management statistics structures contain three important resources: technology, information, and people. Finally, it can be surely said that if we desire to stroll with the globalization world, we must have to introduce MIS systems in each area in our country. We need to make cognizance of the humans about the new technology and systems and it benefits.

Based on these barriers plus different underlying issues that arise from the principal discussion, the following hints are suggested: -There be an extended monitoring of MIS so as to keep away from falling victims of unobserved MIS which has dire ramifications. -Managers and commercial enterprise proprietors need to find a way of tailoring facts in a way that it matches more than a few choice making procedures in variant businesses. -The management ought to motivate the effectuation of a together interdependent and balanced MIS the place people and automatic structures are dealt with with due respect. -Business entities have to locate a way inculcating teaching about new MIS in order to minimize the style of companies being left in the back of on new inceptions. -A well-defined decision-making system ought to be fledged in organizations so as to grant a viable working environment for MIS. A proper area to start here would be the inception of a centralized region the place all decisions in organizations are channeled via -Business managers have to ensure that they appoint (or alternatively outsource) professional personnel who are in a position to ardently run both MIS and the selection making technique.

\section{Acknowledgement}

I would like to thank my lecture Mr. K.M. Nafiul Haque for the valuable advice and supervise me. I would additionally like to thank the CEO of Humac lab Mr. MD. MUBIR M. CHOWDHURY who helped me in providing with knowledge expertise for giving the ordinary information about the corporation system.

\section{References}

1] CHOWDHURY, MD.MUBIR M. "Important of Management Information System in Business.” Mar. 2018.

[2] BillalurrahmanRony. "Applications Of MIS in Bangladesh Management Information Systems Are Distinct." Course Hero, www.coursehero.com/file/p225gkb0/Applications-Of-MIS-in-BangladeshManagement-information-systems-are-distinct/.

[4] Helal, Muhammad, and Mahjabeen Rahman. "Bangladesh's IT Industry." The Daily Star, The Daily Star, 2 Dec. 2016, www.thedailystar.net/op-ed/bangladeshs-itindustry-1324174.

[5] Top 14 Management Information System (MIS) Reports." Your Article Library, 19 Dec. 2015, www.yourarticlelibrary.com/management/information-system/top-14management-information-system-mis-reports/70214.

[6] The Role of Management Information Systems." Smartsheet, 27 Oct. 2017, www.smartsheet.com/management-information-systems. "Management Information Systems: Managing the Digital Firm.: Kenneth C. Laudon: 
9780273754596: Amazon.com: Books.” Amazon, Amazon, Aug. 2011, www.amazon.com/Management-Information-Systems-Managing-

Digital/dp/0273754599.

[7] Government Launches National Scale-up of Electronic Management Information System (EMIS)." Dhaka Tribune, eleven Oct. 2017, www.dhakatribune.com/health/2017/10/12/government-launches-national-emis.

[8] Management Information Systems: Managing the Digital Firm." Pearson Education, Mercury Reader | Pearson, www.pearson.com/us/highereducation/product/Laudon-Management-Information-Systems-Managing-theDigital-Firm-15th-Edition/9780134639710.html.

[9] Management Information Systems (MIS)." Inc.com, Inc., www.inc.com/encyclopedia/management-information-systems-mis.html.

[10] Adeoti-Adekeye. (1997). The importance of administration facts systems. MCB Bank. Library Review, forty six (5), 318-327.

[11] Lee, A.S., (2001), Editorial. MIS Quarterly, 25(1), iii-vii.

[12] Laudon, K.C. and Laudon, J.P. (2003). Management Information Systems: Managing the Digital Firm (Upper Saddle River, NJ: Prentice Hall).

[13] Baskerville, R.L. and Myers, M.D., (2002), Information systems as a reference discipline. MIS Quarterly, 26(1), 1-14.

[14] Alavi, M. and Carlson, P. (1992), A assessment of MIS lookup and disciplinary development. Journal of Management Information Systems, 8(4), 45-62.

[15] Handzic Meliha (2001). Does More Information Lead to Better Informing, The Bank of New South Wales, Australia. [Online] Available: http://ecommerce.lebow.drexel.edu/eli/pdf/hanEBKDoesM.pdfAccessed on22ndFebruary 2011.

[16] Liu, S and Young, R.I.M (2007). An exploration of key information fashions and their relationships in international manufacturing choice support, Proc. IMechE, Journal of Engineering Manufacture, 21(1), 711-724. DOI:10.1243/09544054JEM531,http://dx.doi.org/10.1243/09544054JEM531.

[17] Walsham, G. (2001). Making a world of difference: IT in a international context. Chichester/New York:Wiley.

[18] Walsham, G. (2002). Cross-cultural software program production and use: A structurational analysis. MIS Quarterly, 26(4), 359-380.

\section{Copyrights}

Copyright for this article is retained by the author(s), with first publication rights granted to the journal.

This is an open-access article distributed under the terms and conditions of the Creative Commons Attribution license (http://creativecommons.org/licenses/by/4.0/) 